\title{
Covariability between tree-ring-based precipitation reconstructions in Northwest China and the sea-surface temperature of the Indian and Pacific Oceans
}

\author{
Keyan Fang ${ }^{1, *}$, Xiaohua Gou ${ }^{1, * *}$, Fahu Chen ${ }^{1}$, Jinbao $\mathrm{Li}^{2}{ }^{2}$ Feifei Zhou ${ }^{1}$, Yingjun $\mathrm{Li}^{1}$ \\ ${ }^{1}$ Key Laboratory of Western China's Environmental Systems (Ministry of Education), Lanzhou University, \\ 222 South Tianshui Road, Lanzhou 73000, China \\ ${ }^{2}$ International Pacific Research Center, School of Ocean and Earth Science and Technology, University of Hawaii, Honolulu, \\ Hawaii 96882, USA
}

\begin{abstract}
We investigated the coherent variability between precipitation variations in NW China and the sea-surface temperatures of the Indian and Pacific Oceans, using both instrumental data and tree-ring-based precipitation reconstructions. Major coherent hydroclimatic variations in NW China were identified based on the first 2 leading singular value decomposition modes. The modes include the 'southern Xinjiang' pattern, the 'coherent NW-SE' pattern with positive or negative loadings over both the northwestern and southeastern parts and the 'NW-SE dipole' pattern, with inverse correlation patterns between them. The southerly winds near the western boundary of NW China and Lake Balkhash during the early stage of the Indian summer monsoon influence the hydroclimate variability in western NW China (Xinjiang area). The East Asian summer monsoon variability is related to the hydroclimate of eastern NW China, which is modulated by the El Niño Southern Oscillation, geopotential heights in northeastern Asia and over the Philippine Sea, as well as the western Subtropical Pacific High. The strength of the geopotential height in northeastern Asia may be related to the 'coherent NW-SE' pattern, while the inverse relationships between the Pacific Decadal Oscillation and Indian summer monsoon and westerlies may account for the 'NW-SE dipole'.
\end{abstract}

KEY WORDS: NW China - Precipitation reconstruction - Singular value decomposition · Asian monsoon Resale or republication not permitted without written consent of the publisher

\section{INTRODUCTION}

The short for which instrumental climate records exist and the sparse distribution of recording stations across populous East Asia limit our ability to place recent climate events into the larger context of climate change, challenging our efforts to understand and predict climate change (Böhner 2006, Cook et al. 2010). Tree-ring data have been used in response to this problem, by extending climate records back for centuries to millennia for vast regions of East Asia (Zhang et al. 2003, Liu et al. 2004, Shao et al. 2005, Liang et al. 2006, Gou et al. 2007, Fang et al. 2009) and have been used to reconstruct the leading climate modes for large areas (Fang et al. 2010). The establishment of numerous drought-sensitive tree-ring chronologies and the development of the so-called 'point-by-point' regression method make comprehensive climate field reconstructions possible (Cook et al. 2010). Such 
reconstructed drought atlases would be invaluable for mirroring future climate change and understanding regional drought regimes.

A number of studies have noted divergent patterns of drought variability in the western and eastern portions of NW China (Shi et al. 2007, Chen et al. 2008, Fang et al. 2010); these may be a consequence of changes in the drought regimes in the 2 areas. Previous studies have revealed the influence of both westerlies and the Asian summer monsoon on the hydroclimate in NW China (Chen et al. 2008). Wang \& Ho (2002) divided Asian summer monsoon systems into the tropical monsoons of the Indian summer monsoon (ISM) and western North Pacific summer monsoon (WNPSM) and the subtropical East Asian summer monsoon (EASM). Asian monsoon systems have been shown to be modulated by various factors, including heating of the troposphere by the Tibetan Plateau (Böhner 2006), thermal gradients between the Eurasian continent and tropical oceans (Kumar et al. 1999, Duan et al. 2006), Indian and Pacific sea-surface temperatures (SSTs) and the shift of prevailing winds (Webster et al. 1998). Until recently, most attention has been paid to the relationships between Asian monsoons and SSTs (Webster et al. 1998).

In order to investigate the covariability between droughts and SST over a long time period, we employed instrumental data and tree-ring-based precipitation reconstructions of 26 stations in NW China that were derived from a 160 station dataset covering mainland China for the period 1951-2008 (courtesy of the National Climate Center at Beijing, http://ncc. cma.gov.cn/cn/) (Fang et al. 2011). Our study region in NW China ( 35 to $50^{\circ} \mathrm{N}$, 73 to $110^{\circ} \mathrm{E}$ ) is characterized by an arid, continental climate, and water availability plays a significant role in the population's daily life. The network of tree-ring chronologies for NW China and vicinity (e.g. Mongolia) is denser and has been established longer than in other regions of China, which guarantees the reliability of tree-ring-based reconstructions for this region. The purpose of the present study was to determine which factors drive the climate in NW China, by exploring its coherent variability with SST using the singular value decomposition (SVD) method (Bretherton et al. 1992), as well as the linkages between the dominant SVD modes and the geopotential height and wind fields in East Asia.

\section{DATA AND METHODS}

\subsection{Study region}

Fig. 1 shows the locations of 26 meteorological stations in NW China, as well as the prevailing winds for the summer half-year (April-September) at $850 \mathrm{hPa}$ (averaged from 1871 to 2008). It appears that the prevailing winds in NW China are propagated from the northwestern border (northern Xinjiang), probably westerlies, and from the southeastern and southwestern (southern Xinjiang) areas by the Asian summer monsoon. However, the southwestern wind flux weakens sharply near the border of NW China (Fig. 1) when it reaches the high ranges of, for example, the Kunlun Mountains (Yu et al. 2003). The precipitation patterns in NW China agree well with the distribution of wind fields, with relatively humid con-

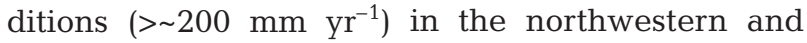
southeastern portions of NW China and particularly dry conditions $\left(<60 \mathrm{~mm} \mathrm{yr}^{-1}\right)$ in the middle of NW China (Yu et al. 2003). According to instrumental records of the 26 stations in NW China, the peak monthly precipitation in western NW China (Xinjiang) occurs in July, followed by June and May, and the peak monthly precipitation in eastern NW China occurs in August, followed by July. That is, the peak seasonal precipitation in Xinjiang is from May to July, while the peak seasonal precipitation in eastern NW China is from July to August. This is consistent with previous studies showing that precipitation peaks earlier in Xinjiang than in eastern NW China (Qian \&

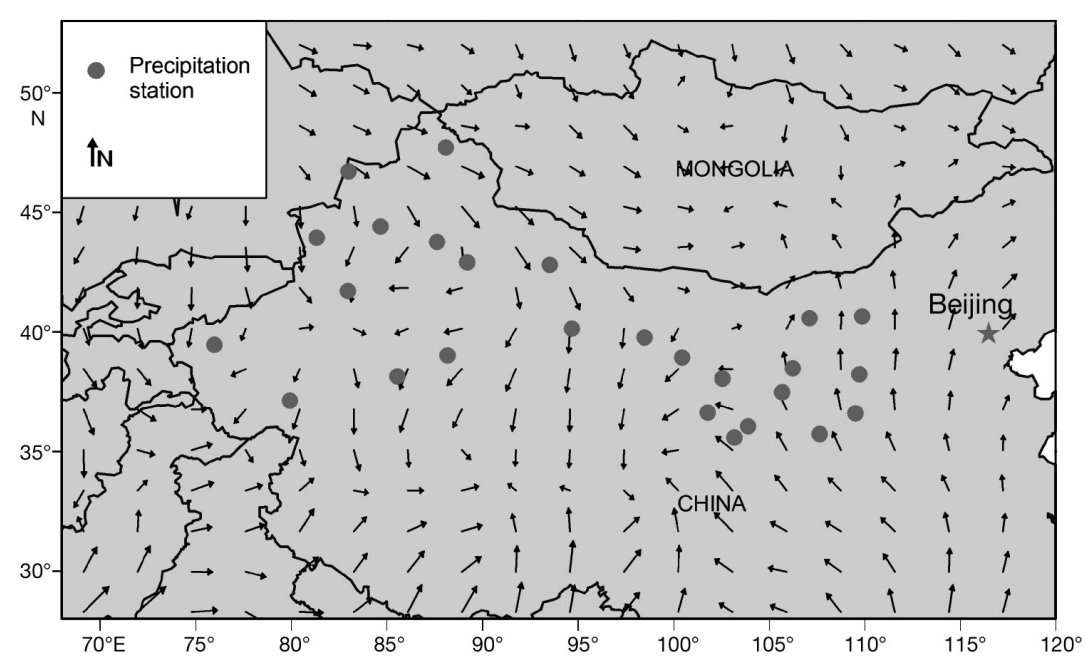

Fig. 1. Locations of the precipitation stations in northwestern China. Vector winds are also shown for the summer half-year (April-September) at $850 \mathrm{hPa}$ (derived from the Twentieth Century Reanalysis [V2] averaged for the period from 1871 to 2008) 
Qin 2007). In order to highlight this difference in the seasonal distributions of monthly precipitation, we excluded January, February, November and December in calculations of the seasonal precipitation for the first (March to June) and second (July to October) half-years, as these months experience limited precipitation. As indicated in Fig. 2, more precipitation occurred in the first half of the year (March to June) in Xinjiang, while more precipitation was seen in the second half of the year (July to October) in eastern NW China. An even higher percentage of precipita-
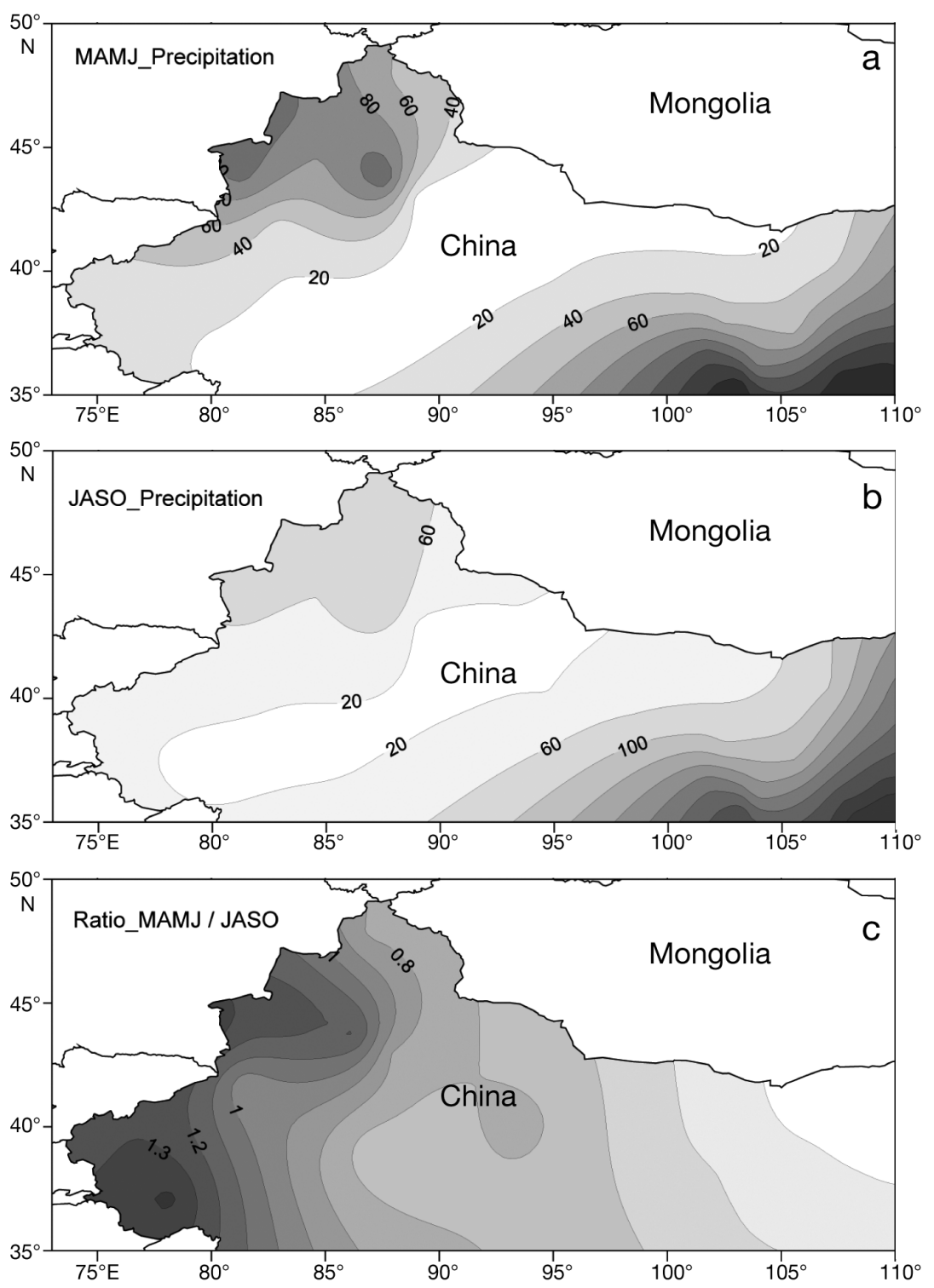

Fig. 2. Contour maps of the total seasonal precipitation (mm) in (a) MAMJ (March-June) and (b) JASO (July-October) in NW China, calculated from the 26 meteorological stations used in the present study (see Fig. 1) for the period since 1951. (c) The ratio between the precipitation in the 2 periods

(MAMJ/JASO) tion in the first half of the year was observed in the dry southwestern area of NW China, as indicated by the ratio between precipitation in the first and second half-years (Fig. 2c).

\subsection{Tree-ring-based precipitation reconstruction}

Tree-ring data from 132 chronologies were collected from old-growth coniferous forests in the unevenly distributed mountainous areas in NW China where relatively abundant precipitation is available (Fang et al. 2011). The climate data targeted for reconstruction were the seasonal precipitation amounts at 26 stations in NW China, averaged from January to October, excluding the precipitation in the months November and December. This is because the mean monthly temperatures at the 26 stations are below or near the freezing point in November and December, which should prohibit cambial activity (Rossi et al. 2006). Reconstructions were performed using the point-bypoint method to locate the tree-ring chronologies near a target precipitation station that would serve as candidate predictors; these were subsequently screened using correlations between climate and tree rings to exclude chronologies insensitive to precipitation values (Fang et al. 2011). The retained tree-ring predictors were processed by principal component analysis (PCA) to generate orthogonal eigenvectors. The orthogonal tree-ring eigenvectors $>1$ were entered into the regression model. In order to facilitate evaluation of the severity of the most recent drought, instrumental data that were not used for the calibration of tree rings were added to reconstructions after matching the mean and variance of the reconstructions and instrumental data during their overlapping period (Fang et al. 2011). The overlapping period for all reconstructions was from 1802 to 1990 , and the longest series was for the Hetian station from 1711 to 2008. 


\subsection{SST, geopotential height and wind data}

We correlated the actual and reconstructed moisture changes over China with a recent version of the extended reconstruction sea-surface temperature (ERSST V3b) (Smith et al. 2008). This gridded dataset spans the period from 1854 to the present, with a $2^{\circ} \times$ $2^{\circ}$ resolution. The authors determined the SST values for the Indian and Pacific Oceans $\left(20^{\circ} \mathrm{S}\right.$ to $60^{\circ} \mathrm{N}$; $40^{\circ} \mathrm{E}$ to $\left.90^{\circ} \mathrm{W}\right)$, which cover much of the area affected by the Asian summer monsoon. One needs to keep in mind, however, that the signal strength of this dataset was dampened prior to 1880 due to the limited availability of data (Smith et al. 2008). In addition, we correlated the coherent patterns of moisture reconstruction and SST with the geopotential height and zonal $(\mathrm{u})$ and merdional (v) winds at $850 \mathrm{hPa}$ in East Asia $\left(10-60^{\circ} \mathrm{N} ; 50-140^{\circ} \mathrm{E}\right)$ in order to better understand the related patterns of atmospheric circulation. The geopotential height and wind data were extracted from the NCEP-NCAR Twentieth Century Reanalysis (V2), and covered a time span from January 1871 to December 2008 (Compo et al. 2006).

\subsection{Singular value decomposition}

SVD is an efficient method for identifying coupled modes between 2 fields because it is easy to implement and yields readably interpretable results (Bretherton et al. 1992). This method is widely used in climatological studies (Bretherton et al. 1992, Lau \& Weng 2001, Yang \& Lau 2004). The singular values identified in the cross-covariance matrix between 2 fields are distributed according to their importance (i.e. the portion of variance explained), whereby only important singular values are included to generate a set of reduced dimension (Bretherton et al. 1992). The correlations are calculated between time series of the 2 transformed fields for each mode, and inhomogeneous correlations are used to evaluate the influence of one mode over the other. In the present study, we used this method to decompose the covariance matrix between the moisture variability in NW China (the observational and reconstructed precipitation dataset) and the SSTs in the Pacific and Indian Oceans. The SVD analyses were implemented during 3 overlapping periods of moisture variables and SST, i.e. 18541900, 1901-1950 and 1951-2008, periods with nearly equal lengths of $\sim 50$ yr. One still needs to keep in mind that, in particular cases, SVD may produce modes without physical meaning (Yang \& Lau 2004). Therefore, we investigated the potential link between SVD modes and the relevant atmospheric circulation patterns to test whether the modes were physically interpretable. In addition, the SVD modes were compared with previously identified moisture patterns in NW China (Shi et al. 2007, Fang et al. 2010).

\section{RESULTS}

The first 2 leading SVD modes explained 63.0, 61.3 and $76.2 \%$ of the precipitation-SST covariance for the reconstructed periods of 1854-1900 and 19011950 and the instrumental period after 1951 (Table 1); these modes were retained in the following analyses because of their considerable cumulative variances. The explained variances of the 2 leading SVD modes during the reconstruction periods were lower than those seen during the instrumental period, possibly due to the loss of variance in the proxy-based reconstructions. Precipitation data were significantly and positively correlated $\left(\mathrm{r}_{0.01}=0.44\right)$ with the associated SST variability for each pair of SVD modes (Table 1), suggesting stable links between them. Their relationships, however, are better illustrated through the heterogeneous correlation maps, which describe the correlation between the variability of each grid and the leading SVD mode of the other field (Bretherton et al. 1992), as shown in Figs. 3, 4 \& 5 for the reconstruction periods 1854-1900 and 1901-1950 and the instrumentation period since 1951.

As shown in Fig. 3c, high correlations were seen over the southwestern part of NW China (southern Xinjiang), which we termed the 'southern Xinjiang' pattern, corresponding to high correlations with the SST in the Arabian Sea (Fig. 3d). As shown in Figs. 3a $\& 5 a$, negative correlations were found over north-

Table 1. Percentage variance and cumulative variance of the precipitation-sea-surface temperature covarying patterns explained by the 2 leading singular value decomposition (SVD) modes during the periods 18541900, 1901-1950 and after 1951, as well as correlations between the time series of the associated leading SVD modes

\begin{tabular}{|lcccccc|}
\hline & \multirow{2}{*}{$1854-1900$} & \multicolumn{2}{c}{ 1901-1950 } & \multicolumn{2}{c|}{ 1951-2008 } \\
& SVD1 & SVD2 & SVD1 & SVD2 & SVD1 & SVD2 \\
\hline Percentage variance & 0.336 & 0.294 & 0.396 & 0.217 & 0.441 & 0.321 \\
Cumulative variance & & 0.630 & & 0.613 & & 0.762 \\
Correlation & 0.449 & 0.678 & 0.472 & 0.447 & 0.624 & 0.500 \\
\hline
\end{tabular}




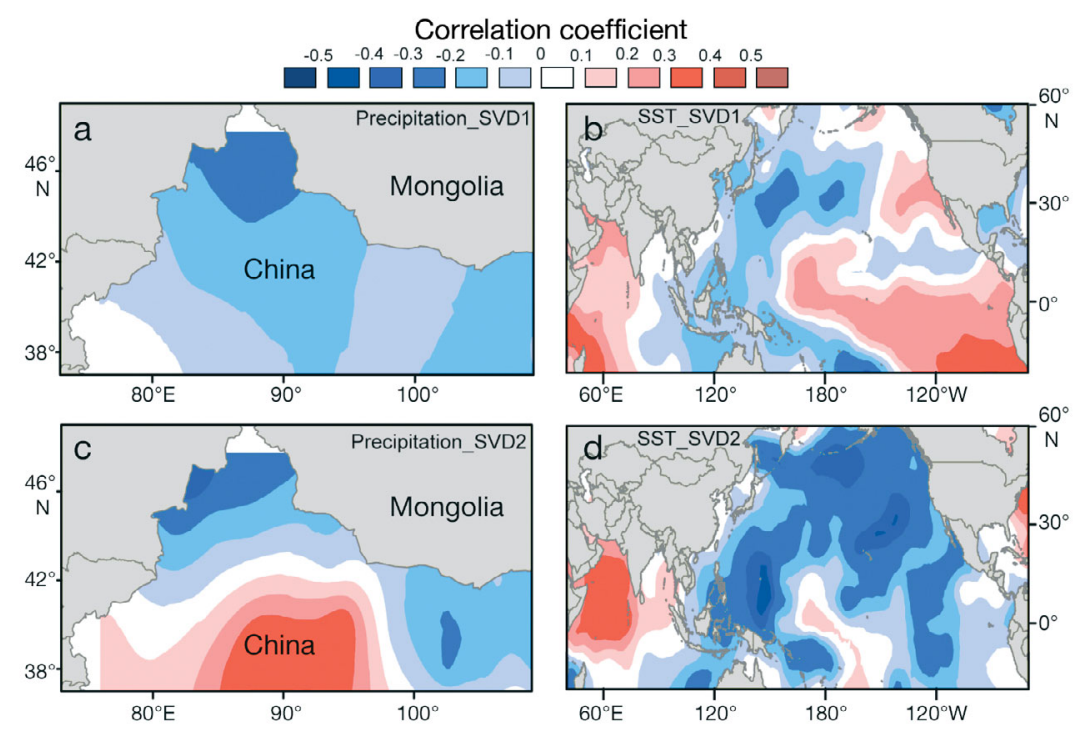

Fig. 3. Heterogeneous correlation maps of the first 2 leading singular value decomposition (SVD) modes $(\mathrm{a}, \mathrm{b})$ SVD1 and $(\mathrm{c}, \mathrm{d})$ SVD2 of $(\mathrm{a}, \mathrm{c})$ precipitation in NW China and $(\mathrm{b}, \mathrm{d})$ the sea-surface temperatures (SST) of the Indian and Pacific Oceans over the reconstruction period 1854-1900. Insignificant correlations (0.1 level) were masked out

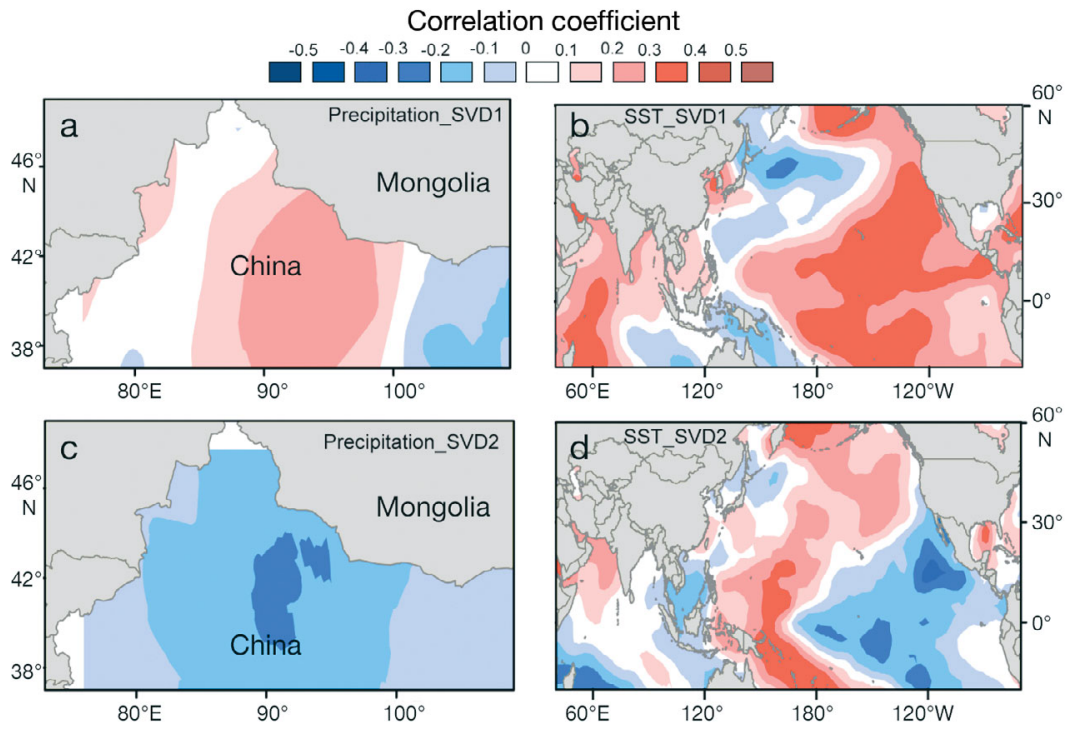

Fig. 4. Heterogeneous correlation maps as for Fig. 3, but for the instrumental period 1901-1950 for the warm phases of both the El Niño-Southern Oscillation (ENSO) and Pacific Decadal Oscillation (PDO) (Mantua et al. 1997). In Fig. 4, the patterns in Panels $\mathrm{c}$ and $\mathrm{d}$ show some similarity with those in Panels a and $b$, except for the absence of a divergent pattern in the southeastern area and an eastward shift in the horseshoelike SST correlation pattern. It appears the Pacific Ocean (ENSO-like SST patterns) was closely linked to the hydroclimate in NW China during the period 1901-1950, and the Indian Ocean may have played a more important role after 1951, as evidenced by more significant correlations with SST in the Indian Ocean. Positive correlations between the leading SVD time series, with geopotential height at $850 \mathrm{hPa}$ in subtropical regions and negative correlations at mid-latitudes, were found during the warm phases of both the ENSO and PDO for the period 1901-1950 (Fig. 6). Negative correlations in northeastern Asia were observed between the time series of the leading SVD modes during dry conditions in the period after 1951, with geopotential height at $850 \mathrm{hPa}$, (Fig. 7). Correlations between the leading SVD modes during the instrumentation period and the wind field at $850 \mathrm{hPa}$ indicate the existence of a cyclic pattern over northeastern Asia and intensified westward and southward winds near the western boundary of NW China (Fig. 8), corresponding to the coherent precipitation-SST variability observed during the instrumental period (Fig. 5).

\section{DISCUSSION}

\subsection{ISM and NW droughts}

'NW-SE dipole' pattern can be seen in Fig. 5c, with positive correlations over the northwestern area and negative correlations over southeastern NW China. This 'NW-SE dipole' corresponds to positive correlations over the eastern and central tropical Pacific, with a horseshoe-like negative correlation band surrounding the dipole (Figs. 4b \& 5d)-typical patterns
Persistent linkages were found between wet conditions in western NW China (Xinjiang) with warm SST in the northern Indian Ocean, which correspond to above-normal geopotential height at $850 \mathrm{hPa}$ over the Indian and western Pacific Oceans (Fig. $7 \mathrm{c}, \mathrm{d}$ ). 

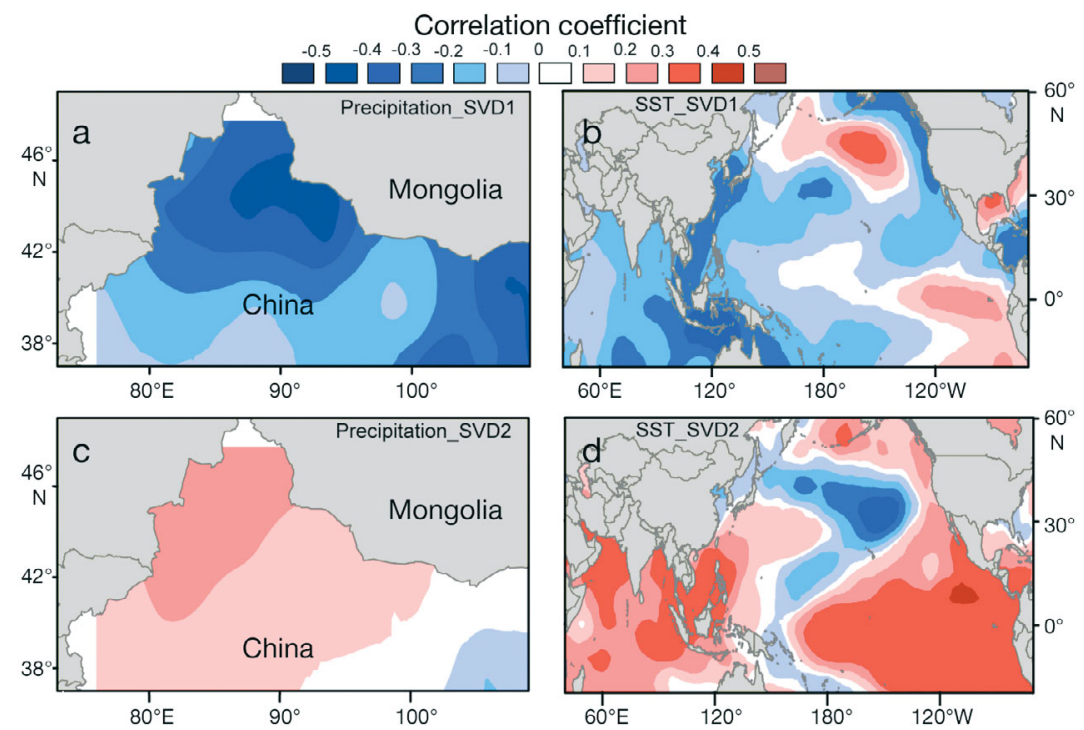

Fig. 5. Heterogeneous correlation maps as for Fig. 3, but for the instrumental period 1951-2008
Accordingly, as shown in Fig. 8d, intensified southward winds near Lake Balkhash correspond to wet conditions in western NW China (Fig. 5c). It appears the ISM influenced moisture variability in western NW China, which is in agreement with previous studies (Li et al. 2010). The mean wind vector map shown in Fig. 1 also illustrates that southward winds reach the southern boundary of NW China. The water vapor propagated by the ISM may be able to reach NW China from the moisture flux near Balkhash (Fig. 8). The intensified ISM may also impact the NW China pattern by transporting water vapor further north and then joining the westerlies (see below) to impact the
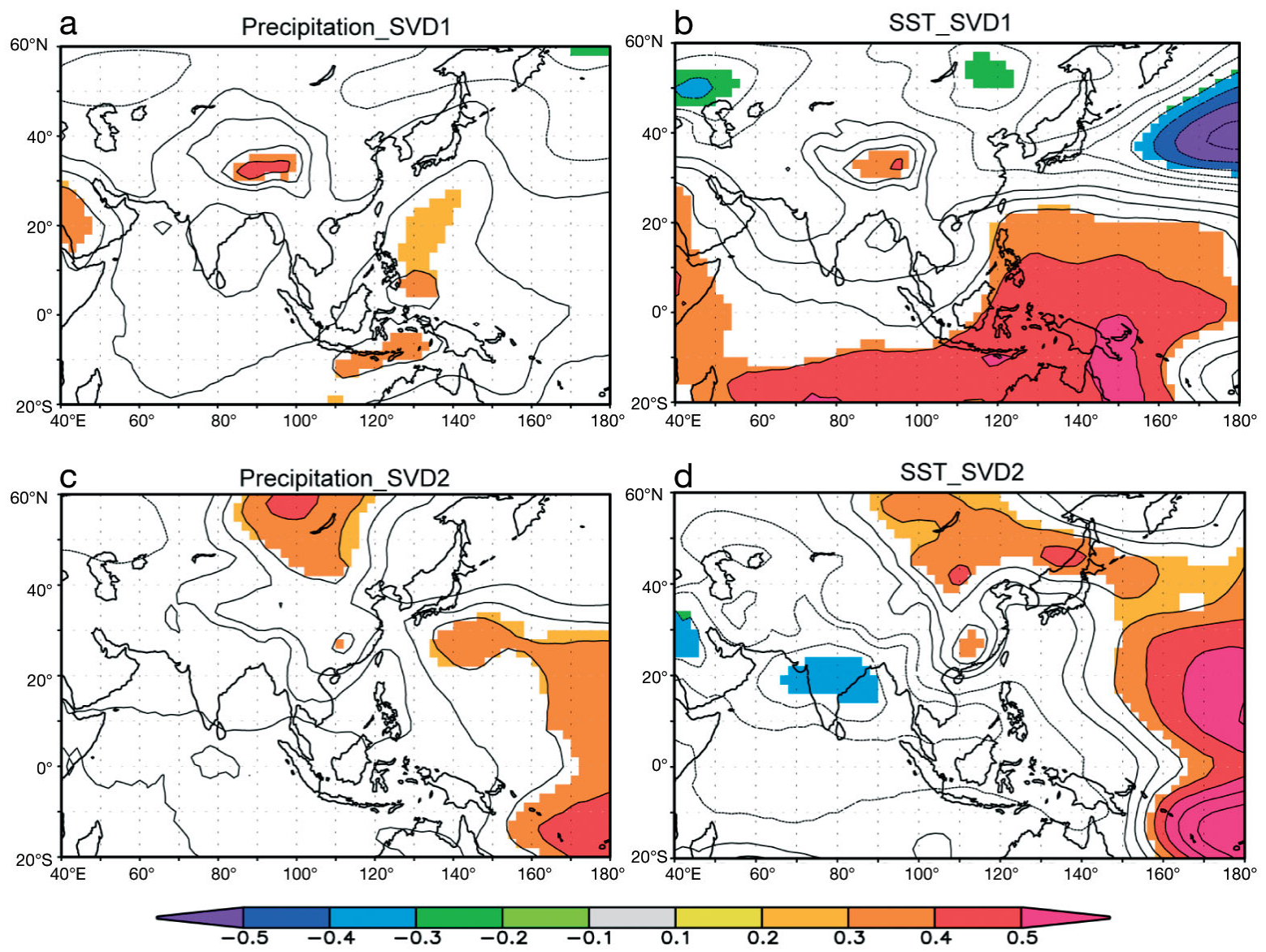

Fig. 6. Heterogeneous correlation maps of the first 2 leading singular value decomposition (SVD) modes (a,b) SVD1 and (c,d) SVD2 of $(\mathrm{a}, \mathrm{c})$ precipitation and $(\mathrm{b}, \mathrm{d})$ the sea-surface temperatures (SST) at $850 \mathrm{hPa}$ geopotential height for East Asia. The $850 \mathrm{hPa}$ geopotential height data were derived from the Twentieth Century Reanalysis (V2) Correlations were calculated during the reconstruction period 1901-1950. Insignificant correlations (0.1 level) were masked out 

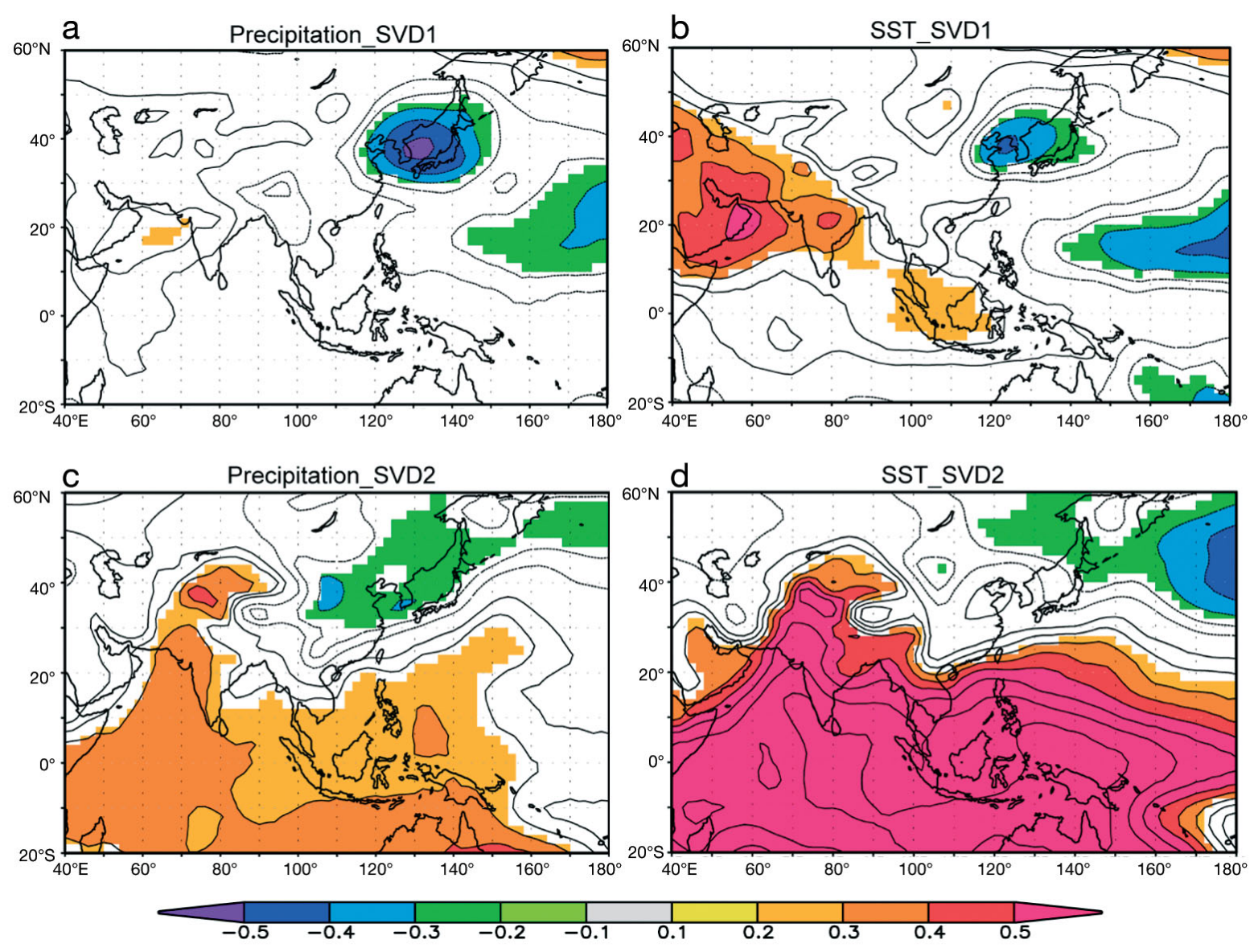

Fig. 7. Heterogeneous correlation maps as for Fig. 6, but for the instrumental period 1951-2008

hydroclimate in northern Xinjiang. This is consistent with the previous division of the regions influenced by the Asian monsoon (Ramage 1971). An earlier study found that the tropical Somali Jet was able to reach Xinjiang via the western boundary of the Tibetan plateau and that the Indian Ocean was an important moisture source for Xinjiang (Yang \& Zhang 2007). It is worth noting that some studies found that the ISM has limited prospects for transporting water vapor from the Indian Ocean into Xinjiang by way of the eastern boundary of the Tibetan Plateau and across the Tibetan Plateau (Tian et al. 2001, Chen et al. 2008). There are also previous results demonstrating that the ISM is capable of impacting the moisture variability in NW China via the topographic channels along the northern borders of the Tibetan Plateau (Yu et al. 2003). The characteristics of the drought regime over Xinjiang remain uncertain, and further modeling studies are required.

The earliest onset of the Asian monsoon is seen over the Indochina peninsula or the eastern equatorial Indian Ocean in late April or May; subsequently, the monsoon extends to the Bay of Bengal and Arabian Sea till late May. The entire Indian subcontinent is under the influence of the ISM by the middle of July, in its late stage (Wang \& Ho 2002, Ding 2004). The hydroclimatic variations for the precipitation reconstruction season from January to October appear closely related to the variations in the early stage of the ISM. The southern branches of westerlies are strong during the early stage of the ISM (Böhner 2006). The influences of the early stage of the ISM on western NW China agree well with the seasonal distribution of precipitation in Xinjiang (Fig. 2), with a higher ratio of precipitation in May and June, relative to eastern NW China, and with a smaller portion of precipitation in spring and early summer. More attention needs to be paid to the early stage of the ISM when considering moisture variability in the western part of NW China (Xinjiang). There may be differences in the variability of the early stage of the ISM.

Weakened (intensified) ISMs tend to be found during El Niño (La Niña) events, when the subsidence of 

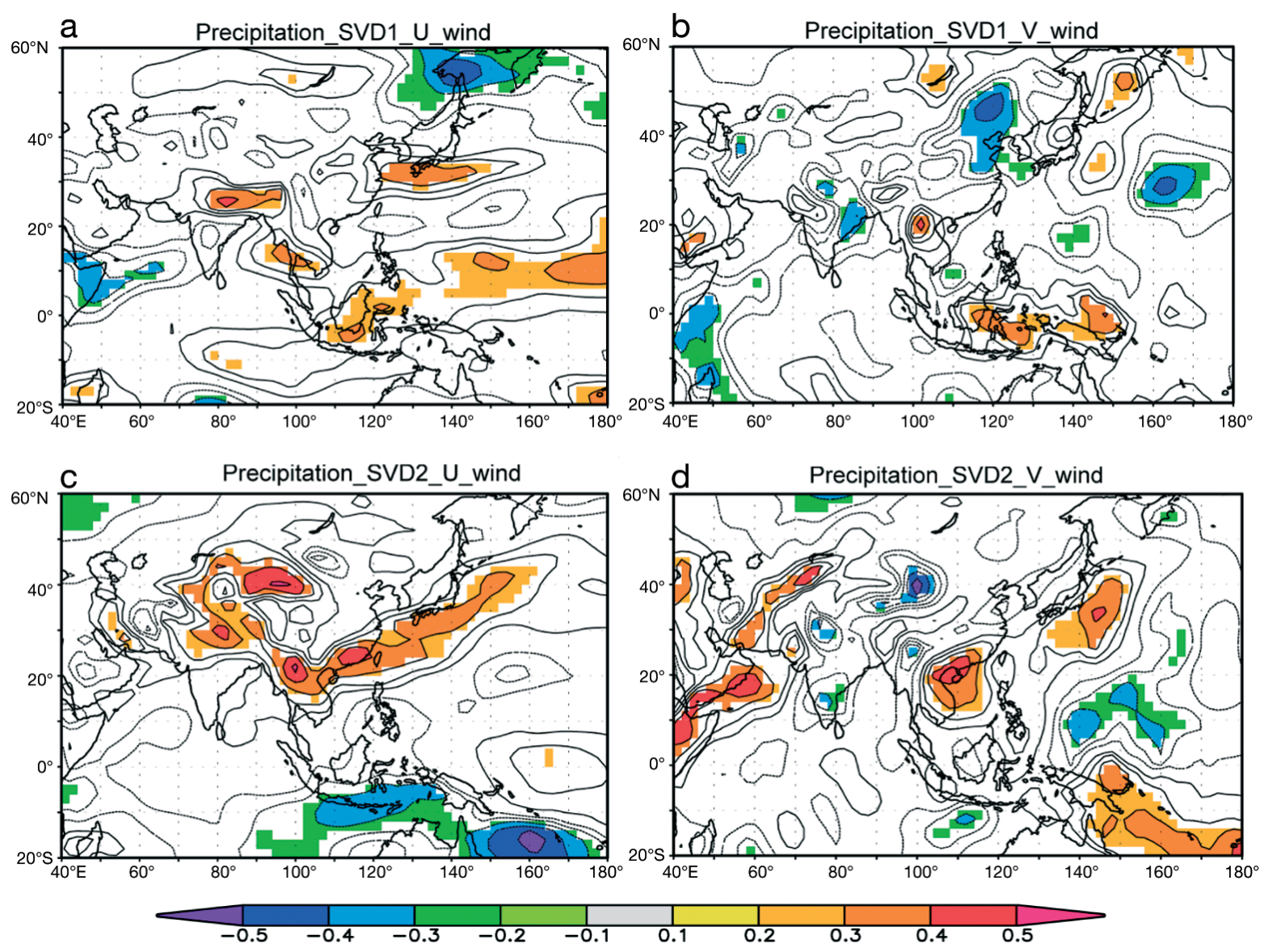

Fig. 8. Heterogeneous correlation maps of the first 2 leading singular value decomposition (SVD) modes (a,b) SVD1 and (c,d) SVD2 of $(\mathrm{a}, \mathrm{c})$ precipitation and zonal $(\mathrm{u})$ winds and $(\mathrm{b}, \mathrm{d})$ the sea-surface temperatures (SST) and meridional $(\mathrm{v}) \mathrm{winds}$ at $850 \mathrm{hPa}$ (derived from the Twentieth Century Reanalysis [V2]). Insignificant correlations (0.1 level) were masked out

the Walker circulation suppresses the convective wind over the Indian region (Kumar et al. 1999). It is reasonable that dry (wet) conditions in western NW China correspond to El Niño (La Niña) events and the associated weakened ISM (Fig. 3a,b). However, wet (dry) conditions in western NW China are also found during El Niño (La Niña) events for both reconstructed and observation periods (Figs. 4a,b \& 5c,d), which may be an indicator of the unstable inverse ISM-ENSO relationship (Kumar et al. 1999, Feng \& $\mathrm{Hu}$ 2004, Singhrattna et al. 2005). Potential reasons include the southeastward shift of the Walker circulation or the strengthened ISM that is beyond the influence of the ENSO (Kumar et al. 1999). Another potential reason is that the variability in the early stage of the ISM influencing NW China is not so closely related to the ENSO. The ISM may have become more influential regarding the moisture variability in western NW China since 1951, as indicated by increased correlations with Indian SST (Fig. 5d) and the ISM trough (Fig. $7 \mathrm{c}, \mathrm{d}$ ).

\subsection{EASM and ENSO}

The shift of the rising limb and the subsidence part are key reasons accounting for the ENSO-Asian summer monsoon linkages (Kumar et al. 1999, Singhrattna et al. 2005). In years with abnormally high SSTs over the eastern and central equatorial Pacific, the descending limb of the Walker circulation could suppress the convective activity over the Philippine Sea, resulting in a weakened EASM (Zhang et al. 1999, Wang et al. 2001, Yang \& Lau 2004, Lu 2005, Singhrattna et al. 2005). The strength of the EASM is related to moisture variations in the eastern part of NW China (Li \& Zeng 2002). Although the relationships between the ENSO and droughts in western NW China are variable, as indicated above, the inverse relationships between the ENSO and droughts in eastern NW China appear relatively stable (Figs. 3a,b, 4a,b \& $5 \mathrm{c}, \mathrm{d})$, consistent with previous investigations indicating a more stable ENSO-EASM relationship (Feng \& Hu 2004). The subsidence over the Philippine Sea dur- 
ing the mature phase of the ENSO is associated with an anticyclone that tends to delay the shift of western Pacific High to its northern and western boundary in late summer, leading to a weakened EASM (Zhang et al. 1999, Yang \& Lau 2004, Lu 2005, Li et al. 2008). As shown in Fig. 7a,b, the weakened Subtropical Pacific High coincides with the drying trend in the eastern NW China.

A strengthened anticyclone in northeastern Asia occurs with abnormal southward or southeastward winds from the west, which transport more water vapor into northern China, possibly reaching the eastern part of NW China. As shown in Fig. 7a,b, low pressures over northeastern Asia correspond to dry conditions over eastern NW China (Fig. 5a). Accordingly, a cyclonic pattern correlates with wind fields over the Sea of Japan (Fig. 8a,b). In addition, an anticyclone (cyclone) is an indicator of a strong (weak) ISM and thus wet (dry) conditions in western NW China (Wang et al. 2001). Therefore, the existence of the cyclone pattern may be one factor accounting for the 'coherent NW-SE' (Fig. 5a).

\subsection{Westerlies and droughts in NW China}

Westerlies prevail over the western and northern parts of NW China (Fig. 1) and are associated with pressure gradients between the Aleutian Low and Subtropical High (Böhner 2006). A wetting tendency is seen for western NW China (Fig. 5c) in periods with an above-normal western Subtropical Pacific High and below-normal Aleutian Low (Figs. 6a,b \& $7 \mathrm{c}, \mathrm{d})$, corresponding to strengthened westerlies during a positive phase of the PDO (Mantua et al. 1997). The PDO can modify the strength of the Siberian High pressure cell in winter, with a positive (negative) PDO related to the weakened (intensified) strength of the EASM (Li et al. 2004). In accordance with increased pressure gradients, intensified westward winds are seen near Lake Balkhash, which transport water vapors into western NW China (Fig. 8c). The NW-SE dipole pattern may result from the inverse relationships between PDO-westerly associations and the PDO-EASM linkages, which determines the drought regimes of the northwestern and southeastern parts of NW China, respectively. Similarly, previous studies also documented that the wetting (drying) trend in western NW China and the drying (wetting) tendency in the eastern part are associated with the warm (cold) phase of the ENSO (Zhang et al. 1999, Yang \& Lau 2004, Lu 2005, Li et al. 2010), which is consistent with SST correlations in the tropical Pacific (Figs. 4c \& 5d). This suggests that the 'NW-SE dipole' may be more significant during the warm and cold phases of both the ENSO and PDO.

The strength of westerlies is linked to the summer Mongolian Low. The wind vector field, shown in Fig. 1, indicates the existence of a cyclone-like pattern over Mongolia in the summer. That is, lower (higher) geopotential height over Mongolia is often associated with deeper-than-normal (less intense) westerlies (Figs. 7c,d \& 8c,d), leading to wetter (dryer) conditions in western China (Fig. 5c). The westward wind near the southern boundary of the Mongolia Low in summer joins these westerlies and thus strengthens the westward wind that impacts NW China.

An observed drying trend in eastern NW China since the late 1970s may have resulted from decay of the EASM (Wang et al. 2001, Li \& Zeng 2002, Shi et al. 2007, Fang et al. 2010). For the western part of NW China, the increasing influence of the ISM, as indicated above, and intensified westerlies may have been related to the wetting trend observed since the 1980s (Li \& Wang 2003, Shi et al. 2007, Fang et al. 2010). Meanwhile, the strength of the early stage ISM that impacts the precipitation in Xinjiang may have increased. The increase in precipitation over western NW China may also be related to the potentially intensified evaporation caused by warminginduced snowmelt and the enlarged artificial oasis. Future studies aimed at quantifying the contributions of intensified human activities, such as irrigation, would be helpful in clarifying the influence of atmospheric circulations on moisture variability in NW China. We also stress the need for future studies that are based on more reliable reconstructions, with more tree-ring predictors available.

\section{CONCLUSIONS}

Using the SVD methodology, tree-ring based precipitation reconstructions were employed to explore the coherent variability between the hydroclimate in NW China and the SST in the Indian and Pacific Oceans for the periods of 1854-1900, 1900-1950 and 1951-2008. Distinct patterns were identified through heterogeneous correlation maps of the first 2 leading SVD modes of precipitation variability in NW China, namely, the 'southern Xinjiang' pattern, the 'coherent NW-SE' pattern and the 'NW-SE dipole' pattern. Correlations between the first 2 leading SVD modes and geopotential height and the wind fields were calculated to investigate the link to atmospheric cir- 
culations. The early-stage ISM plays an influential role on drought variations in western NW China via the southward wind near Lake Balkhash, which may be responsible for the 'southern Xinjiang' pattern. The strength of the EASM, which impacts the hydroclimatic variations in eastern NW China, is modulated by the ENSO, by geopotential heights over the Philippine Sea and northeastern Asia, and by the western Subtropical Pacific High. The cyclonic pattern over northeastern Asia results in decay of the ISM and dry conditions in eastern NW China, which may be responsible for the 'coherent NW-SE' pattern. The pressure gradient between the subtropical region and the Aleutian Low is an indicator of the intensity of westerlies. The inverse relationships between the PDO with westerlies and the EASM may account for the 'NW-SE dipole'. During the reconstruction period, the increasing influence of the ISM on western NW China and the strengthened westerlies may be factors influencing the wetting trend that has been observed since the 1980s. Decay in the EASM may be responsible for the drying tendency in recent decades in the eastern NW China.

Acknowledgements. The authors acknowledge the kind help from Jia Sun and Yang Deng. This research was supported by the National Basic Research Program of China (973 Program) (2009CB421306), the National Science Foundation of China (40971119), the NSFC Innovation Team Project (40721061) and the Chinese 111 Project (B06026).

\section{LITERATURE CITED}

Böhner J (2006) General climatic controls and topoclimatic variations in Central and High Asia. Boreas 35:279-295

> Bretherton CS, Smith C, Wallace JM (1992) An intercomparison of methods for finding coupled patterns in climate data. J Clim 5:541-560

> Chen F, Yu Z, Yang M, Ito E and others (2008) Holocene moisture evolution in arid central Asia and its out-ofphase relationship with Asian monsoon history. Quat Sci Rev 27:351-364

> Compo GP, Whitaker JS, Sardeshmukh PD (2006) Feasibility of a 100-year reanalysis using only surface pressure data. Bull Am Meteorol Soc 87:175-190

Cook ER, Anchukaitis KJ, Buckley BM, D'Arrigo RD, Jacoby GC, Wright WE (2010) Asian monsoon failure and megadrought during the last millennium. Science 328:486-489

Ding Y (2004) Seasonal march of the East-Asian summer monsoon. World Scientific Publishing, Singapore

Duan K, Yao T, Thompson LG (2006) Response of monsoon precipitation in the Himalayas to global warming. J Geophys Res 111:D19110. doi:10.1029/2006JD007084

> Fang K, Gou X, Chen F, Yang M and others (2009) Drought variations in the eastern part of Northwest China over the past two centuries: evidence from tree rings. Clim Res 38:129-135

Fang K, Davi N, Gou X, Chen F, Cook E, Li J, D'Arrigo R
(2010) Spatial drought reconstructions for central High Asia based on tree rings. Clim Dyn 35:941-951

Fang K, Gou X, Chen F, Cook E, Li J, Buckley BM, D'Arrigo R (2011) Large-scale precipitation variability over Northwest China inferred from tree rings. J Clim 24:3457-3468

Feng S, Hu Q (2004) Variations in the teleconnection of ENSO and summer rainfall in northern China: a role of the Indian Summer Monsoon. J Clim 17:4871-4881

> Gou X, Chen F, Cook E, Jacoby G, Yang M, Li J (2007) Streamflow variations of the Yellow River over the past 593 years in western China reconstructed from tree rings. Water Resour Res 43:W06434. doi:10.1029/2009WR 005705

Kumar KK, Rajagopalan B, Cane MA (1999) On the weakening relationship between the Indian monsoon and ENSO. Science 284:2156-2159

> Lau KM, Weng H (2001) Coherent modes of global SST and summer rainfall over China: an assessment of the regional impacts of the 1997-98 El Niño. J Clim 14:1294-1308

Li JP, Wang J (2003) A modified zonal index and its physical sense. Geophys Res Lett 30:1632. doi:10.1029/2003GL 017441

Li J, Zeng Q (2002) A unified monsoon index. Geophys Res Lett 29:1274. doi:10.1029/2001GL013874

Li C, He J, Zhu J (2004) A review of decadal/interdecadal climate variation studies in China. Adv Atmos Sci 21: 425-436

$>$ Li H, Dai A, Zhou T, Lu J (2008) Responses of East Asian summer monsoon to historical SST and atmospheric forcing during 1950-2000. Clim Dyn 34:501-514

Li J, Cook ER, Chen F, Gou X, D'Arrigo R, Yuan Y (2010) An extreme drought event in the central Tien Shan area in the year 1945. J Arid Environ 74:1225-1231

Liang E, Liu X, Yuan Y, Qin N and others (2006) The 1920s drought recorded by tree rings and historical documents in the semi-arid and arid areas of northern China. Clim Change 79:403-432

Liu Y, Shi J, Shishov V, Vaganov E and others (2004) Reconstruction of May-July precipitation in the North Helan Mountain, Inner Mongolia since AD 1726 from tree-ring late-wood widths. Chin Sci Bull 49:405-409

$>$ Lu R (2005) Interannual variation of North China rainfall in rainy season and SSTs in the equatorial eastern Pacific. Chin Sci Bull 50:2069-2073

- Mantua NJ, Hare SR, Zhang Y, Wallace JM, Francis RC (1997) A Pacific interdecadal climate oscillation with impacts on salmon production. Bull Am Meteorol Soc 78: 1069-1079

Qian WH, Qin A (2007) Precipitation division and climate shift in China from 1960 to 2000. Theor Appl Climatol 93:1-17

Ramage CS (1971) Monsoon meteorology. Academic Press, New York, NY

Rossi S, Deslauriers A, Anfodillo T, Carraro V (2006) Evidence of threshold temperatures for xylogenesis in conifers at high altitudes. Oecologia 152:1-12

> Shao X, Huang L, Liu H, Liang E, Fang X, Wang L (2005) Reconstruction of precipitation variation from tree rings in recent 1000 years in Delingha, Qinghai. Sci China Ser D 48:939-949 (Series D)

> Shi Y, Shen Y, Kang E, Li D, Ding Y, Zhang G, Hu R (2007) Recent and future climate change in northwest China. Clim Change 80:379-393

Singhrattna N, Rajagopalan B, Kumar KK, Clark M (2005) Interannual and interdecadal variability of Thailand summer monsoon season. J Clim 18:1697-1708 
Smith TM, Reynolds RW, Peterson TC, Lawrimore J (2008) Improvements to NOAA's historical merged land-ocean surface temperature analysis (1880-2006). J Clim 21: 2283-2296

Tian L, Masson-Delmotte V, Stievenard M, Yao T, Jouzel J (2001) Tibetan Plateau summer monsoon northward extent revealed by measurements of water stable isotopes. J Geophys Res 106:28081-28088

Wang B, Ho L (2002) Rainy season of the Asian-Pacific Summer Monsoon. J Clim 15:386-398

Wang B, Wu R, Lau KM (2001) Interannual variability of the Asian Summer Monsoon: contrasts between the Indian and the western North Pacific-East Asian Monsoons. J Clim 14:4073-4090

- Webster PJ, Magana V, Palmer T, Shukla J, Tomas RA, Yanai M, Yasunari T (1998) Monsoons - processes, predictability, and the prospects for prediction. J Geophys Res 103:14451-14510

Editorial responsibility: Bryson Bates, Wembley, Australia
Yang F, Lau KM (2004) Trend and variability of China precipitation in spring and summer: linkage to sea-surface temperatures. Int J Climatol 24:1625-1644

Yang LM, Zhang QY (2007) Circulation characteristics of interannual and interdecadal anomalies of summer rainfall in north Xinjiang. Chin J Geophys 50:412-419 (in Chinese with English abstract)

Yu Y, Wang J, Li Q (2003) Spatial and temporal distribution of water vapor and its variation trend in atmosphere over northwest China. J Glaciol Geocryol 25:149-156 (in Chinese, English Abstract)

Zhang R, Sumi A, Kimoto M (1999) A diagnostic study of the impact of El Niño on the precipitation in China. Adv Atmos Sci 16:229-241

Zhang QB, Cheng GD, Yao TD, Kang XC, Huang JG (2003) A 2326-year tree-ring record of climate variability on the northeastern Qinghai-Tibetan Plateau. Geophys Res Lett 30:1739. doi:10.1029/2003GL017425

Submitted: January 25, 2011; Accepted: June 7, 2011

Proofs received from author(s): September 14, 2011 